\title{
CEREBRAL ACTING MAPS OF HYDRALAZINE, CLONIDINE, AND $\alpha$-METHYLDOPA IN SPONTANEOUSLY HYPERTENSIVE RATS AS DEMONSTRATED BY THE ${ }^{14} \mathrm{C}$-DEOXY-D-GLUCOSE METHOD
}

\author{
Tetsuo HAYASHI and Keiji NAKAMURA* \\ Department of Pharmacology. Nippon Roche Research Center, Kamakura 247. Japan
}

Accepted May 25, 1982

\begin{abstract}
In spontaneously hypertensive rats, the ${ }^{14} \mathrm{C}$-deoxy-D-glucose method was applied to examine the response of glucose utilization rate (GUR), as a measure of the neuronal activity, of 102 cerebral nuclei to the equivalent fall in blood pressure by about $50 \mathrm{mmHg}$ after the treatment with hydralazine, clonidine, and $\alpha$-methyldopa. All drugs significantly increased GUR in the dorsal medullary nuclei, whereas the drugs decreased it in the n. tegmenti ventralis, substantia reticularis mesencephali, some hypothalamic periventricular nuclei, amygdala nuclei, and n. accumbens septi. Hydralazine (but not other drugs) decreased GUR in the $n$. parabrachialis ventralis, $n$. centromedianus, $n$. reticularis medialis and $n$. suprachiasmaticus. Clonidine alone increased GUR in medullary reticular nuclei and decreased it in the infundibulum, n. proprius striae terminalis and cortex entorhinalis. $\alpha$ Methyldopa (but not other drugs) increased GUR in the $n$. reticularis parvocellularis and decreased it in the n. ambiguus, $n$. ventromedialis, area lateralis and anterior hypothalami, area preoptica medialis and n. medialis septi. Both clonidine and $\alpha$-methyldopa (but not hydralazine) increased GUR in the $n$. reticularis thalami and decreased it in the substantia nigra pars compacta and grisea centralis, n. paramedianus, neuroendocrine hypothalamic nuclei, Forel $\mathrm{H}$, and $\mathrm{n}$. lateralis and intermedium septi. Clonidine and $\alpha$-methyldopa did not alter GUR in some suprabulbar nuclei responsive to hydralazine. Thus, the non-traumatic deoxyglucose method could be applied successfully to identify cerebral acting sites of clonidine. $\alpha$ methyldopa and hydralazine in SHR.
\end{abstract}

Clinical introduction of centrally acting hypotensive drugs has given a clue for understanding the role of the central nervous system in the etiology of essential hypertension. Nevertheless, the acting site and mechanism of clonidine and $\alpha$-methyldopa are not fully clarified. The application of hydralazine, a vasodilative drug. may give some information for identifying cerebral

\footnotetext{
*To whom reprint requests should be addressed.
}

nuclei sensitive to the decreased baroreceptor afferent impulses after a fall in blood pressure.

The ${ }^{14} \mathrm{C}$-deoxy-D-glucose (DG) method. developed by Sokoloff (1) and Sokoloff and colleagues (2), provides the means to cxamine the rates of glucose utilization as a measure of neuronal activity in all macro. scopic structures of the rat brain in serial sections at the rest and conscious state without traumatic, surgical and anesthetic interventions. Present knowledge of cerebral 
topography related to the acting sites of clonidine and $\alpha$-methyldopa and the baroreceptor reflex arc has been based respectively on evidence derived from anesthetized animals and neuroanatomical findings with diffuse labelling of anterograde transport of labelled amino acids and retrograde transport of horseradish peroxidase (3) and terminal degeneration after placing electrolytic lesions (4).

The present study was designed to map centrally acting sites of hydralazine, clonidine and $\alpha$-methyldopa and partly the baroreceptor mediated alteration of neuronal activity in the brain of adult spontaneously hypertensive rats (SHR).

\section{MATERIALS AND METHODS}

Studies were performed on male SHR raised in our animal facility when they reached the age of 20 weeks. Aortic blood pressure was measured without anesthesia and restraint with a pressure transducer through a catheter implanted chronically into the aorta near the orifice of the renal artery via the femoral artery. Heart rates were triggered through pulses of aortic blood pressures. The aortic blood pressure and heart rate of conscious SHR were $198 \pm 5$ $\mathrm{mmHg}$ and $380 \pm 25$ beats/min $(n=8)$. respectively. For inducing an equivalent decrease in blood pressure of about $50 \mathrm{~mm} \mathrm{Hg}$, hydralazine $(5 \mathrm{mg} / \mathrm{kg})$, clonidine $(0.1 \mathrm{mg} /$ $\mathrm{kg}$ ), or $\alpha$-methyldopa $(250 \mathrm{mg} / \mathrm{kg}$ ) were administered orally to SHR (Fig. 1).

For injection of ${ }^{14} \mathrm{C}-\mathrm{DG}$, a polyethylene catheter was implanted into the carotid artery two days previous to the experiment. The conscious, resting animals were injected intra-artery with $165 \mathrm{\mu Ci} / \mathrm{kg}$ of ${ }^{14} \mathrm{C}-\mathrm{DG}$ (homogeneously labelled, specific activity of $326 \mathrm{mCl} / \mathrm{mmole}$; New England Nuclear) and the animals were sacrificed by decapitation $45 \mathrm{~min}$ later when ${ }^{14} \mathrm{C}$-DG phosphate levels in the brain reached a pla- teau (2). Hydralazine. clonidine, and $\alpha$ methyldopa were administered at 1, 3, and $5 \mathrm{hr}$ before sacrifice, respectively.

The brains were removed and processed for autoradiography as described previously (2. 5). From each frozen brain, about 110 sections $(100 \mu \mathrm{m})$ were cut serially, mounted on glass cover slips, and dried on a hot plate at $60^{\circ} \mathrm{C}$. Autoradiographs were prepared in $X$-ray cassettes by exposing the dried sections to Kodak XR-1 medical $X$-ray films for 20 days. ${ }^{14} \mathrm{C}$-Methylmethacrylate standards including a blank and a series of 7 different ${ }^{14} \mathrm{C}$-levels were placed in the cassette. The silver granule density of the autoradiograph was measured with a microdensitometer (Gamma Scientific Corp.) in areas of $200 \mathrm{~km}$ diameter using simultaneously developed autoradiographs of ${ }^{14} \mathrm{C}$ methylmethacrylate plates as references. For calculating the glucose utilization rate, the arterial blood was collected through the implanted carotid catheter to measure glucose and ${ }^{14} \mathrm{C}-\mathrm{DG}$ concentrations in the plasma immediately before and at 5,20, and 45 min after the injection of ${ }^{14} \mathrm{C}-\mathrm{DG}$. Plasma glucose was assayed by the glucose oxidase method (Roche kit).

For calculating the rate of glucose utilization (GUR), the following modified equation (5) based on that of Sokoloff et al. (1977) was used:

$$
\begin{array}{r}
\operatorname{GUR}(t)=d t^{-1} \cdot d\left[C_{M}(t) \cdot\left\{\int_{0}^{t} C^{*}{ }_{p}(t) d t\right\}^{-1} .\right. \\
\left.\int_{0}^{t} C_{p}(t) d t\right] .
\end{array}
$$

In the equation, $C_{M}(t), C^{*}{ }_{p}(t)$, and $C_{p}(t)$ were tissue ${ }^{14} \mathrm{C}-\mathrm{DG}-6$-phosphate, plasma ${ }^{14} \mathrm{C}$-DG, and plasma glucose levels, respectively.

Brain anatomy and terminology were as described by König and Klippel (6). For statistical analysis, the Student's $t$-test was employed.

\section{RESULTS}

Alteration of aortic blood pressure and 
heart rate of conscious SHR after acute treatment of hydralazine, clonidine, and $\alpha$ methyldopa: Figure 1 shows the effect on aortic blood pressure and heart rate of SHR in the resting state after the oral administration of each drug. Hydralazine (5 mg/ $\mathrm{kg}$. p.o.) rapidly lowered blood pressure and gradually increased heart rate (Fig. 1. left panel). Clonidine $(0.1 \mathrm{mg} / \mathrm{kg}$, p.o.) significantly lowered blood pressure and heart rate (Fig. 1. middle panel). $\alpha$-Methyldopa (250 $\mathrm{mg} / \mathrm{kg}$. p.o.) gradually and progressively lowered blood pressure and slightly elevated heart rate 5 hr later (Fig. 1, right panel).

Glucose utilization rate of cerebral nuclei in SHR and normotensive Wistar Kyoto rats (WKY): As summarized in Table 1, glucose utilization varies considerably throughout the brain. In both SHR and WKY, high glucose utilization was detected in the nucleus ( $n$.) olivaris superior, $n$. interpeduncularis, $n$. corporis mamillaris medialis and lateralis, $\mathrm{n}$. caudatus, tuberculum olfactorium, and cortex cingularis and frontalis. These areas were metabolically active structures in the brain. In SHR, there was a marked increase in glucose utilization in the dorsal medullary nuclei, some reticular nuclei, hypothalamic periventricular nuclei and some amygaala nuclei, as compared to those of normotensive WKY, in agreement with previous findings (5).

Effect of hydralazine on glucose utilization rate of cerebral nuclei in SHR: Hydralazine ( $5 \mathrm{mg} / \mathrm{kg}$, p.o.) significantly increased GUR in the $n$. intercalatus, n. commissuralis, area postrema, n. tractus solitarii (caudal part), n. dorsalis nervi vagi, n. olivaris superior, $n$. centralis superior, $n$. reticulotegmentalis pontis, $n$. tegmentalis pedunculopontinus, area lateralis hypothalami, and cortex cingularis (Table 1).
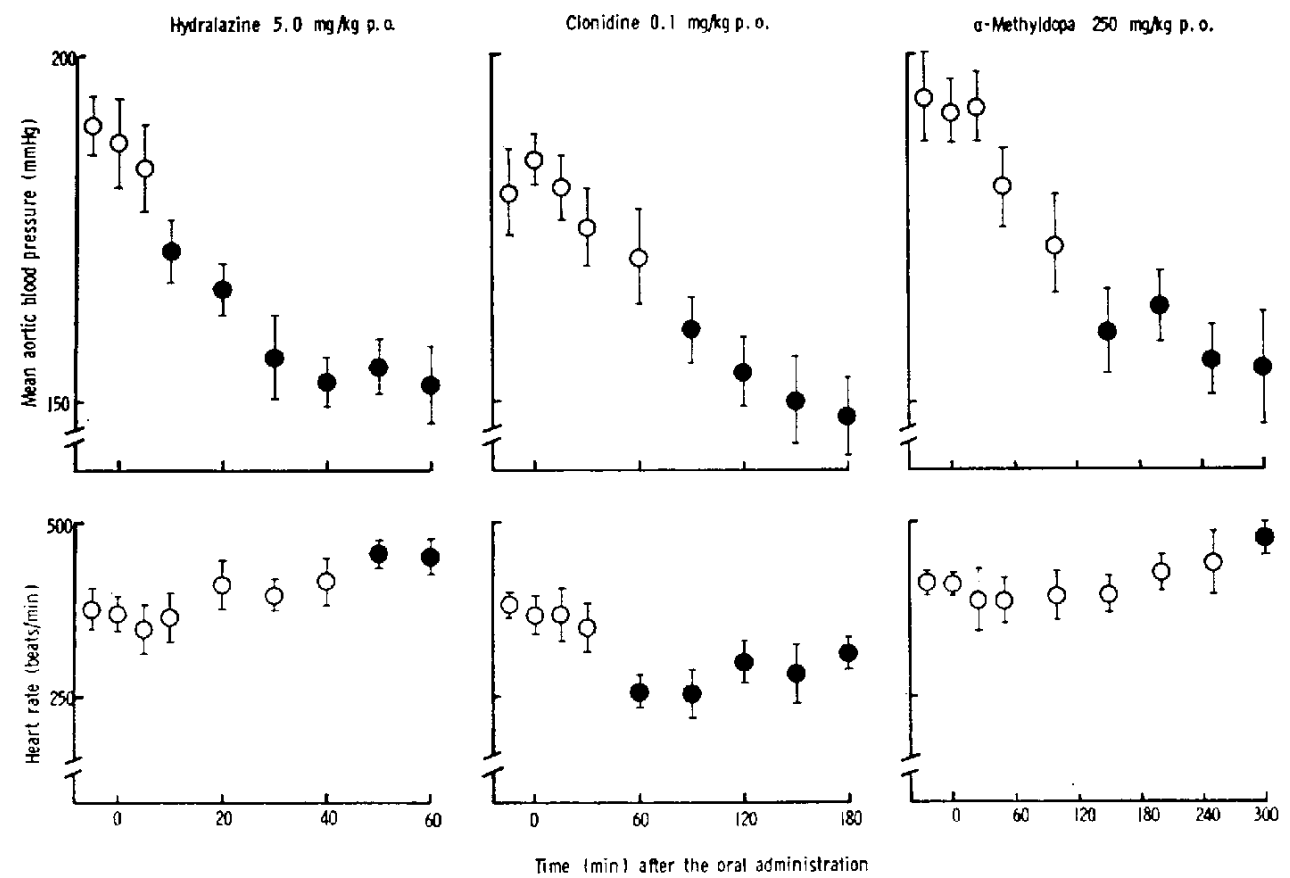

Fig. 1. Effects of oral administration of hydralazine, clonidine, and a-methyldopa on aortic biood pressure and heart rate of adult SHR in the resting and coriscious state. Data are means $\pm S$.E.M. for 5 animals. Closed circles are values significantly $(P<0.05)$ different from the initial values. 


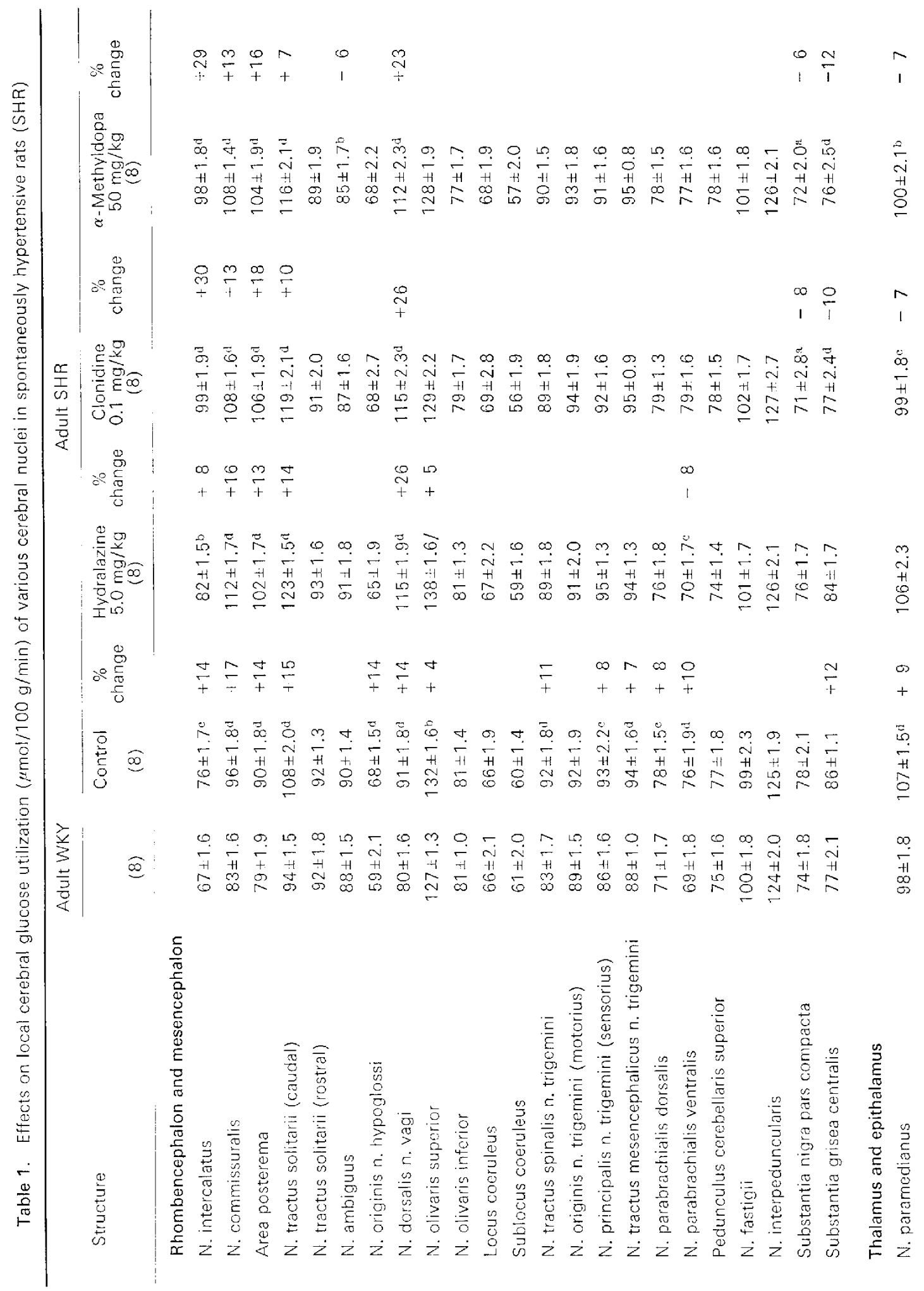


N

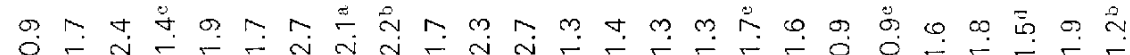

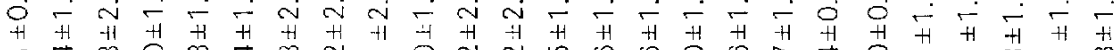

$\nabla$ m $\infty$ o $+4+1+4$

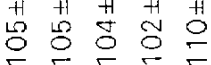

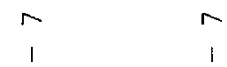

$\vec{\partial}+\sigma$ オ

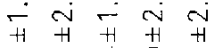
\% 8085

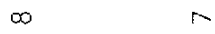

$\infty \infty \mathrm{\infty}$

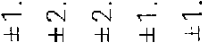
○。

$\nabla r-d \sigma$ i $\sim$ i $\begin{array}{llll}H & H & H\end{array}$ $\infty$ ब 55

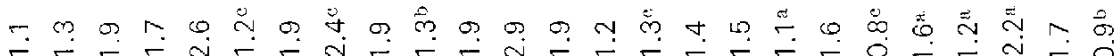

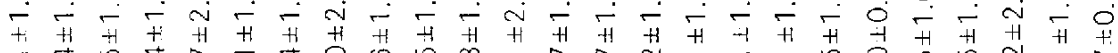

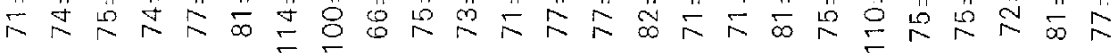

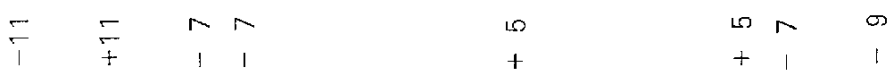

? H H

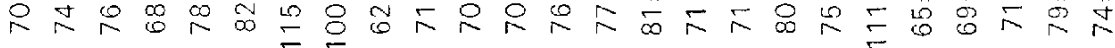

$$
\begin{array}{llllll}
\pi & 0 & 0 & 0 & 0 & 9 \\
++ & + & + & \div & +
\end{array}
$$

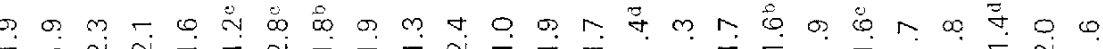
广H H H

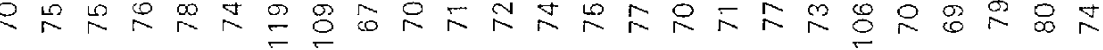

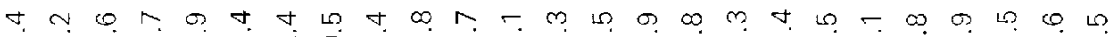

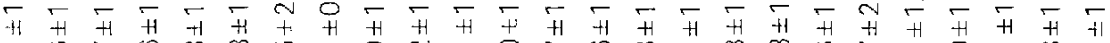

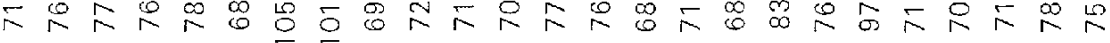
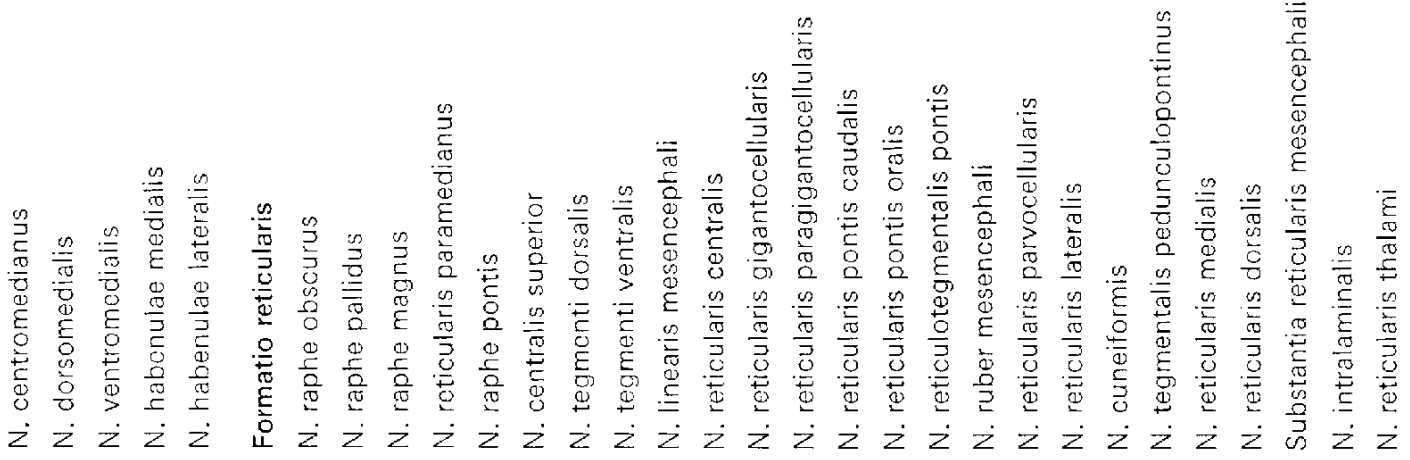


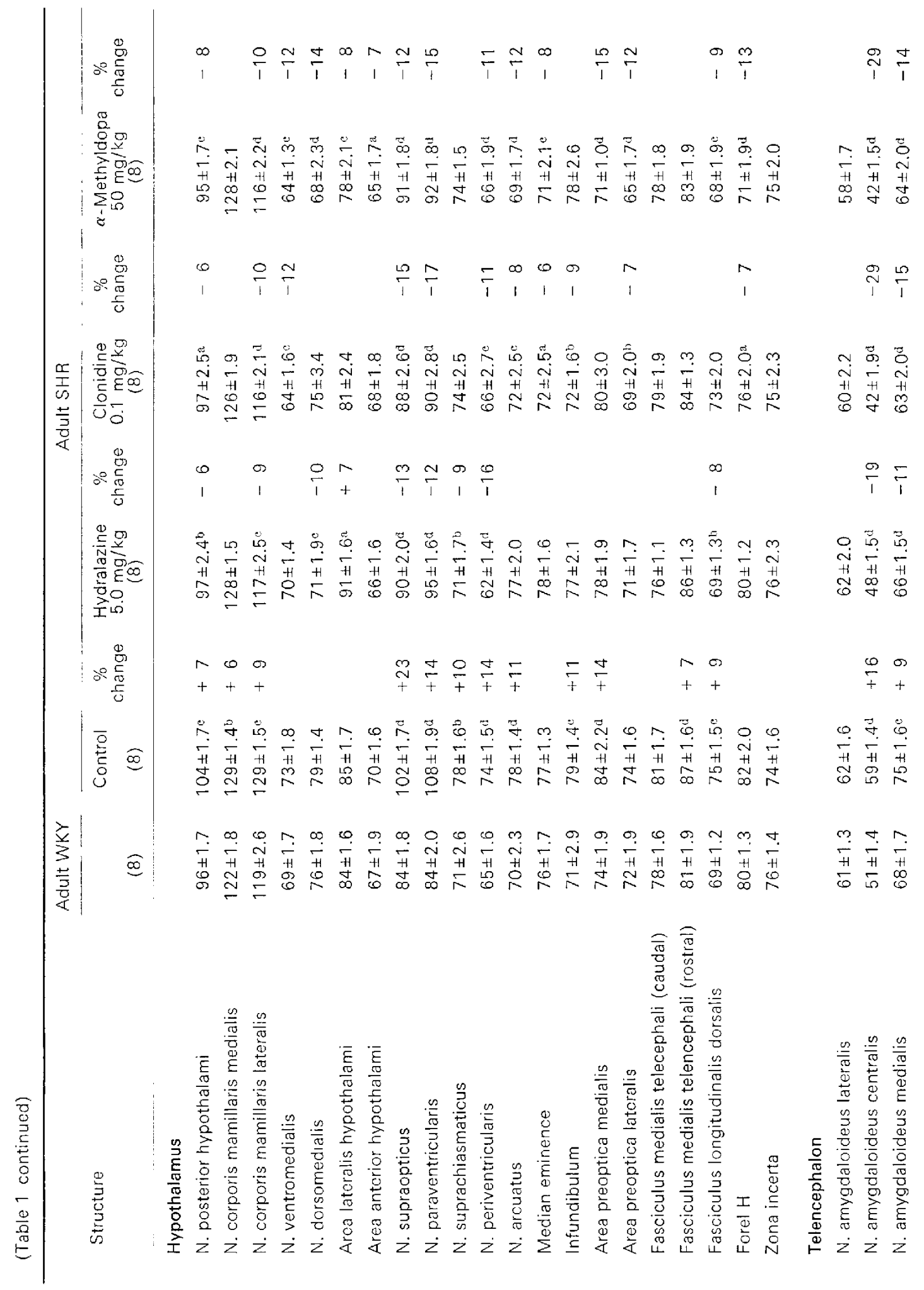




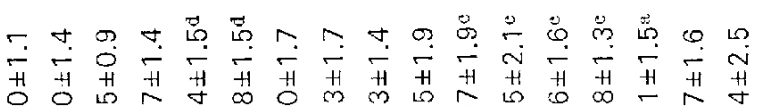

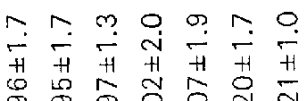

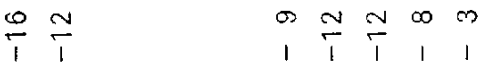

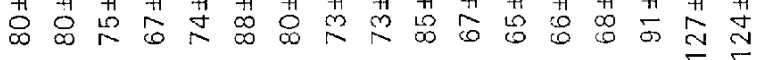
品

$$
\stackrel{10}{i} \underset{1}{1}
$$$$
\infty \propto \sigma
$$

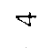

ナ.

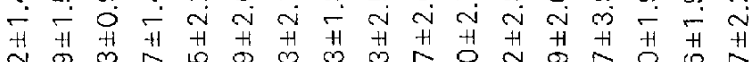

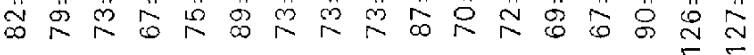

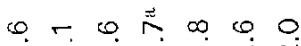
广்

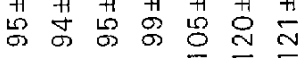

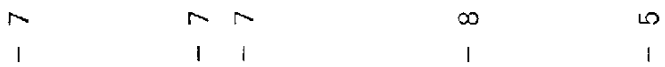

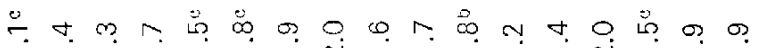

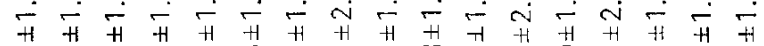

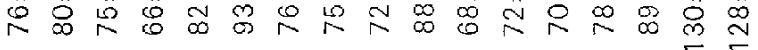

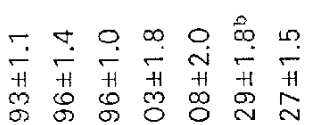

$$
\stackrel{\sim}{+}
$$

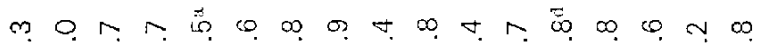

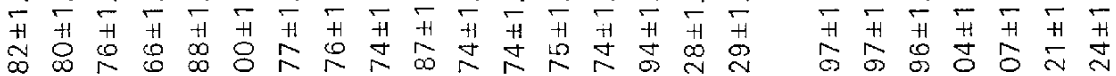
$\varphi$ ๆ

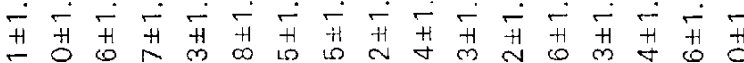

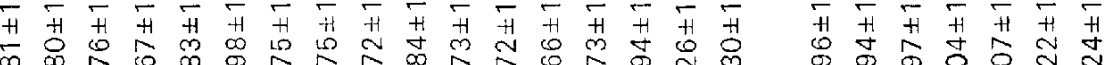

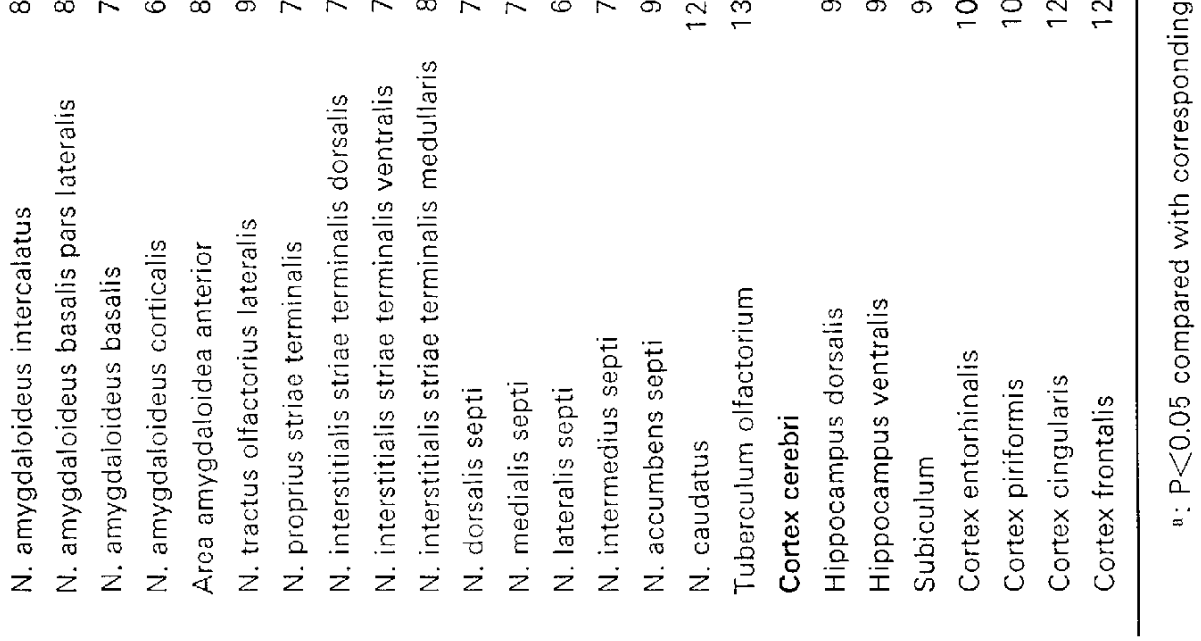


The treatment significantly decreased GUR in the $n$. parabrachialis ventralis, $n$. centromedianus, $n$. habenulae lateralis, brainstem reticular nuclei (n. reticularis paramedianus, $n$. tegmenti ventralis, $n$. linearis mesencephali, n. reticularis medialis and substantia reticularis mesencephali), hypothalamic nuclei (n. posterior hypothalami, n. corporis mamillaris lateralis, $n$. dorsomedialis, $n$. supraopticus, n. paraventricularis, n. suprachiasmaticus and $n$. periventricularis). fasciculus longitudinalis dorsalis, and limbic nuclei (n. amygdaloideus centralis, medialis and intercalatus, area amygdaloidea anterior. n. tractus olfactorius lateralis, $n$. dorsalis, and accumbens septi).

Effect of clonidine on glucose utilization rate of cerebral nuclei in SHR: Clonidine (0.1 $\mathrm{mg} / \mathrm{kg}$, p.o.) significantly increased GUR in the dorsal bulbar nuclei (like hydralazine), $n$. reticularis centralis, $n$. reticulotegmentalis pontis, n. reticularis parvocellularis, n. tegmentalis pedunculopontinus and $n$. reticularis medialis, dorsalis and thalami (Table 1).

The treatment significantly decreased GUR in the substantia nigra pars compacta and substantia grisea centralis, n. paramedianus, n. tegmenti ventralis, substantia reticularis mesencephali, hypothalamic nuclei ( $n$. posterior hypothalami, $n$. corporis mamillaris lateralis, n. supraopticus, n. paraventricularis. $n$. periventricularis, $n$. arcuatus, median eminence, infundibulum and area preoptica lateralis), Forel H, n. amygdaloideus centralis and medialis, area amygdaloides anterior, n. tractus olfactorius lateralis, n. proprius striae terminalis, n. lateralis, intermedius and accumbens septi, and cortex entorhinalis.

Effect of $\boldsymbol{\alpha}$-methyldopa on glucose utilization rate of cerebral nuclei in SHR: $\alpha$-Methyldopa (250 mg/kg p.o.) significantly increased GUR in the dorsal bulbar nuclei, $n$. reticularis parvocellularis, $n$. tegmentalis pedunculopontinus and $n$. reticularis thalami (Table 1 ).

The treatment significantly decreased GUR in the $n$. ambiguus, substantia nigra pars compacta and substantia grisea centralis, n. paramedianus, $n$. ventromedialis thalami, n. habenulae lateralis, $n$. reticularis paramedianus, $n$. tegmenti ventralis, $n$. linearis mesencephali, substantia reticularis mesencephali, hypothalamic nuclei (n. posterior hypothalami. n. corporis mamillaris lateralis. n. ventromedialis, n. dorsomedialis, area lateralis hypothalami, area anterior hypothalami, n. supraopticus, n. paraventricularis, n. periventricularis, n. arcuatus, median eminence, area preoptica medialis and lateralis), fasciculus longitudinalis dorsalis, Forel $H$, and limbic nuclei ( $n$. amygdaloideus centralis and medialis, area amygdaloidea anterior, n. tractus olfactorius lateralis, and n. dorsalis, medialis, lateralis, intermedius and accumbens septi).

\section{DISCUSSION}

The present study indicated that an equivalent fall of blood pressure with all three drugs examined equivalently increased GUR in the dorsal medullary nuclei: n. commissuralis, area postrema. n. tractus solitarii (caudal), and $n$. dorsalis nervi vagi (most extensively). The $n$. tractus solitarii is the primary synaptic site of baroreceptor afferents through the IXth and Xth cranial nerves in the rat (4). The $n$. dorsalis nervi vagi is a main locus of preganglionic vagal neurons in the rat (7). Tachycardiac hydralazine and bradycardiac clonidine produced an equivalent increase in GUR of these nuclei in the dorsal medulla. However, our previous studies (5) also demonstrated that acute hypertension induced by angiotensin II similarly elevated GUR in these dorsal medullary nuclei. The present ${ }^{14} \mathrm{C}$ - DG method thus gave an overall activation of these nuclei in response to either a fall or rise of blood pressure. The enhanced glucose utilization in 
these nuclei is in agreement with the increase in methionine enkephalin-like immunoreactivity in these nuclei $(8,9)$. However, elevation of GUR in these nuclei does not correlate with that of phenylethanolamine $N$ methyltransferase (PNMT) and dopamine $\beta$ hydroxylase $(\mathrm{DBH})$. Hydralazine increased PNMT and DBH activities in the $n$. tractus solitarii area and decreased both enzyme activities in the Al cell area (10).

However, GUR in the n. reticularis medialis was decreased by hydralazine and increased by clonidine. The findings are interesting in view of a modulatory role of the medullary reticular nuclei in the baroreceptor input to cardiac vagal preganglionic neurons $(11,12)$. Tachycardiac action of hydralazine may be due to a baroreceptor mediated reflex after a fall in the blood pressure and also partly due to its direct effect on the myocardium (13. 14) and the brain (15). Clonidine reduced the sympathetic discharges elicited by carotid occlusion (16). Clonidine seems to cause a sensitization to the bradycardiac effects of sinus stimulation. Accordingly, the different response of the $n$. reticularis medialis to clonidine and hydralazine may explain the difference in response of the heart rate to both drugs. Tachycardiac action of $\alpha$ methyldopa in SHR confirmed the previous findings $(17,18)$. Many experiments indicate that a primary site of action of clonidine and $\alpha$-methyldopa may be in the dorsal medulla, probably in the $n$. tractus solitarii (19-23). However, the present results of the same response of these dorsal medullary nuclei, including the $\mathrm{n}$. tractus solitarii and $\mathrm{n}$. dorsalis nervi vagi, to all three drugs could not entirely support the concept that a primary action site of both CNS active drugs was the n. tractus solitarii.

Furthermore, in the suprabulbar nuclei, three drugs equivalently decreased GUR in the $n$. tegmenti ventralis, substantia reticularis mesencephali, and some of hypothalamic and limbic nuclei. Most of these suprabulbar nuclei are responsive in the opposite direction (the increase in GUR) to acute elevation of blood pressure after the treatment with angiotensin $\|$ (5). These nuclei, accordingly, seem to be afferent terminals of baroreceptor impulses through the n. tractus solitarii. The present results are also compatible with the previous findings with anterograde autoradiographic method applied labelled amino acids into the rat $n$. tractus solitarii (3) and electron microscopical terminal degeneration in the rat $(4,24)$. Results on some areas in previous reports are incompatible with those found in the present study. These areas are the stria terminal nuclei, preoptic area and arcuate nucleus (3), and the ventromedial nucleus, median eminence and $n$. reticularis gigantocellularis (24). The discrepancy with the present findings may be explained by traumatic damage of neighboring sites of the n. tractus solitarii or a diffuse injection site of labelled amino acids in the previous studies (3, 4, 24). In accordance with the present findings. our previous study in SHR (18) indicated that all three drugs significantly increased PNMT activity in the n. paraventricularis. The nucleus receives a monosynaptic pathway from cardiovascular neurons in the $n$. tractus solitarii (25).

Clonidine and $\alpha$-methyldopa (but not hydralazine) lowered GUR in the substantia nigra pars compacta, substantia grisea centralis, $n$. paramedianus thalami, $n$. ventromedialis, $n$. arcuatus, median eminence. area preoptica lateralis, Forel $\mathrm{H}$, and $\mathrm{n}$. lateralis and intermedius septi. Autoradiographic studies using $\mathrm{p}-\left[{ }^{3} \mathrm{H}\right]$ aminoclonidine. an $\alpha_{2}$-antagonist, in rat brain slices indicated that high densities of $\alpha_{2}$-receptor were found in the arcuate nucleus, median eminence, and lateral septum (26). They also reported the distribution of $\alpha_{2}$-receptors in the $n$. commissuralis, $n$. tractus solitarii, $n$. supraopticus, hypothalamic periventricular 
areas, and n. amygdaloideus centralis and medialis. The GUR of these nuclei was greatly increased by the treatment with three drugs in the present study. The action of clonidine on the ventral periventricular hypothalamus was also confirmed recently by Rudolph et al. (27). Selective action of clonidine on the brainstem reticular nuclei in the present study also supports the previous findings (28).

It is also interesting to note that clonidine or $\alpha$-methyldopa does not alter GUR in some nuclei responsive to hydralazine. These nuclei were the $n$. olivaris superior, $n$. parabrachialis ventralis, $n$. centromedianus, $n$. reticularis medialis, n. suprachiasmaticus, n. amygdaloideus intercalatus and cortex cinglaris. Clonidine also did not change GUR in the $n$. habenulae lateralis, $n$. reticularis paramedianus, $n$. linearis mesencephali. n. dorsomedialis, area lateralis hypothalami, fasciculus longitudinalis dorsalis and $n$. dorsalis septi which were all responsive to hydralazine. $\alpha$-Methyldopa did not change GUR in such nuclei responsive to hydralazine as the $n$. centralis superior and $n$. reticulotegmentalis pontis. These findings on CNSactive drugs may indicate that both clonidine and $\alpha$-methyldopa also inhibit CNS action due to baroreceptor distension.

In conclusion, the non-traumatic DG method could be applied successfully to explore cerebral acting sites of clonidine, $\alpha$ methyldopa and hydralazine in SHR.

\section{REFERENCES}

1) Sokoloff, L.: Relation between physiological function and energy metabolism in the central nervous system. J. Neurochem. 29, 13-26 (1977)

2) Sokoloff, L., Reivich. M., Kennedy, C., Des Rosiers, M.H., Patlak, C.S., Pettigrew, K.D., Sakurada, $O$. and Shinohara, M.: The [14]deaxyglucose method for the measurement of local cerebral glucose utilization: theory, procedure, and norma! values in the conscious and anesthetized albino rat. J. Neurochem. 28,
897-916 (1977)

3) Ricardo, J.A. and Koh,E.T.: Anatomical evidence of direct projections from the nucleus of the solitary tract to the hypothalamus, amygdala, and other forebrain structures in the rat. Brain Res. 153, 1-26 (1978)

4) Palkovits, M. and Záborszky, L.: Neuroanatomy of central cardiovascular control. Nucleus tractus solitarii: afferent and efferent neuronal connections in relation to the baroreceptor arc. In Hypertension and Brain Mechanisms, Edited by De Jong. W. and Provost. A.P., p. 9-24, Elsevier Sci. Publ. Co. Amsterdam (1977)

5) Hayashi, T. and Nakamura, K.; Cerebral neuronal activity in spontaneously hypertensive rats as demonstrated by the ${ }^{14} \mathrm{C}$-deoxyglucose method. Naunyn-Schmiedeberg's Arch. Pharmacol. 316 , $331-339$ (1981)

6) König, J.F.R. and Klippel, R.A.: The Rat Brain: A Stereotaxic Atlas of the Forebrain and Lower Parts of the Brain Stem. Krieger. Huntington. N.Y. (1970)

7) Lewis, P.R., Scott, A. and Navaratnam, V.: Localization in the dorsal motor nucleus of the vagus in the rat. J. Anat. 107, 197-208 (1970)

8) Nakamura, K. and Hayashi, T.: Altered methionine enkephalin immunoreactivity in cerebral nuclei of spontaneously hypertensive rats. Clin. Expl. Hypertension 4, 297-301 (1982)

9) Nakamura, K, and Hayashi, T.: Methionine enkephalinergic neuronal activity in cerebral nuclei of spontaneously hypertensive rats. Hypertension (1982) (in press)

10) Nakamura, K. and Nakamura, K.: Role of brainstem and spinal noradrenergic and adrenergic neurons in the development and maintenance of hypertension in spontaneously hypertensive rats. Naunyn-Schmiedeberg's Arch. Pharmacol. 305, 127-133 (1978)

11) Miura, M. and Reis, D.J.: Role of the solitary and paramedian reticular nuclei in mediating cardiovascular reflex responses from carotid baro- and chemoreceptors. J. Physiol. 223, 525-548 (1972)

12) Pérez-González, J.F. and Rojas, J.R.: Inhibition of the baroreceptor input to cardiac vagal preganglionic neurons by stimulation of the medullary reticular formation. J. Physiol. 263, 152P-153P (1976)

13) Khatri, I., Usmura, N, Notargiacomo, A. and Freis, E.D.: Direct and reflex cardiostimulatory effects of hydralazine. Am. J. Cardio. 40, 38-42 (1977)

14) Leier, C.V., Desch, C.E., Magorien, R.D., Triffon, D.W., Unverferth, D.V., Boudoulas, H. and Lewis, R.P.: Positive inotropic effects of 
hydralazine in human subiects: comparison with prazosin in the setting of congestive heart failure. Am. J. Cardio. 46, 1039-1044 (1980)

15) Gupta, K.P. and Bhargava, K.P.: Mechanism of tachycardia induced by intracerebro ventricular injection of hydralazine. Archs int. Pharmacodyn. Thér. 155, 84-89 (1965)

16) Hukuhara, T., Otsuka, Y., Takeda, R. and Sakai, F.: Die zentralon Wirkungen des 2-(2.6Dichlorphenylamino) - $\alpha$-imidazolinhydro-

chtoride. Arzneim.-Forsch. 18, 1147-1153 (1968)

17) Ishise, S., Pegram, B.L, and Frohlich, E.D.: Disparate effects of methyldopa and clonidine on cardiac mass and haemodynamics in rats. Clin. Sci. 59, Supp. 6, 449s-452s (1980)

18) Nakamura, K. and Nakamura, K.: Differential effects of $\alpha$-methyldopa, clonidine and hydralazine on norepinephrine and epinephrine synthesizing enzymes in the brainstem nuclei of spontaneously hypertensive rats. Japan. J. Pharmacol. 30, 1-10 (1980)

19) Haeusler, G.: Activation of the central pathway of the baroreceptor reflex, a possible mechanism of the hypotensive action of clonidine. NaunynSchmiedeberg's Arch. Pharmacol. 278, 231$246(1973)$

20) Laubie, J., Schimitt, $H$. and Drouillat, $M$.: Action of clonidine on the baroreceptor pathway and medullary sites mediating vagal bradycardia. Europ. J. Pharmacol. 38, 298303 (1976)

21) Struyker, B., Smeets, G., Brouwer, G. and Van Rossum, J.M.: Central nervous system $\alpha$ adrenergic mechanisms and cardiovascula? regulation in rats. Archs int. Pharmacodyn. Thér. 213, 285 (1975)

22) Rockhold, R.W. and CaldwelI, R.W.: Effect of Iesions of the nucleus tractus solitarii on the cardiovascular actions of clonidine in conscious rats. Neuropharmacology 18, 347-354 (1979)

23) Van Zwieten. P.A.: Antihypertensive drugs with a central action. Progr. Pharmacol. 1, 1-63 (1975)

24) Palkovits, M., Mezey, E. and Záborszky, L.: Neuroanatomical evidence for direct neuronal connections between the brain stem baroreceptor conters and the forebrain areas involved in neural regulation of the blood pressure. In Nervous System and Hypertension. Edited by Meyer, P. and Schmitt, H., p. 18-30. Wiley-Flammarion. Paris (1979)

25) Ciriello, J. and Calaresu, F.R.: Monosynaptic pathway from cardiovascular neurons in the nucleus tractus solitarii to the papaveritricular nucleus in the cat. Brain Res. 193, 529-533 (1980)

26) Young, W.S., III and Kuhar, M.J.: Noradrenergic $\alpha_{1}$ and $\alpha_{2}$ receptors: Light microscopic autoradiographic localization. Proc. natn. Acad. Sci. 77, 1696-1700 (1980)

27) Rudolph, C.D., Kaplan, S.L. and Ganong, W.F.: Sites at which clonidine acts to affect blood pressure and the secretion of renin, growth hormone and ACTH. Neuroendocrinology 31, 121-128(1980)

28) Chan, S.H.H. and Koo, A.: The participation of medullary reticular formation in clonidineinduced hypotension in rats. Neuropharmacology 17, 367-373 (1978) 